\title{
Visible-light-induced bromoetherification of alkenols for the synthesis of $\beta$-bromotetrahydrofurans and -tetrahydropyrans
}

\author{
Run Lin, Hongnan Sun, Chao Yang ${ }^{*}$, Youdong Yang, Xinxin Zhao and Wujiong Xia
}

\author{
Full Research Paper \\ Address: \\ State Key Lab of Urban Water Resource and Environment, the \\ Academy of Fundamental and Interdisciplinary Sciences, Harbin \\ Institute of Technology, Harbin 150080, P. R. China \\ Email: \\ Chao Yang* - xyyang@hit.edu.cn; Wujiong Xia* - xiawj@hit.edu.cn \\ * Corresponding author \\ Keywords: \\ alkenols; bromoetherification; photoredox catalysis; visible light
} \\ Open Access}

Beilstein J. Org. Chem. 2015, 11, 31-36.

doi:10.3762/bjoc. 11.5

Received: 17 October 2014

Accepted: 23 December 2014

Published: 08 January 2015

Associate Editor: T. P. Yoon

(c) 2015 Lin et al; licensee Beilstein-Institut. License and terms: see end of document.

\begin{abstract}
A visible-light-induced photoredox-catalyzed bromoetherification of alkenols is described. This approach, with $\mathrm{CBr}_{4}$ as the bromine source through generation of bromine in situ, provides a mild and operationally simple access to the synthesis of $\beta$-bromotetrahydrofurans and -tetrahydropyrans with high efficiency and regioselectivity.
\end{abstract}

\section{Introduction}

The halocyclization of alkenes provides an excellent synthetic method for halogenated heterocycles [1-3]. In recent years, haloaminocyclization [4,5], halolactonization [6,7] and haloetherification $[8,9]$ of alkenes have received considerable attention from chemists, and various approaches have been made in this area. Initially, the classical synthetic pathway for bromocyclization proceeds utilizing bromine [10]. However, molecular bromine is hazardous and difficult to handle. Further research show that $N$-bromosuccinimide (NBS) is an effective alternative for the bromocyclization [11-14]. Furthermore, Wei Sun and co-workers disclosed an intriguing strategy to access the haloetherfication of alkenols with $N$-chlorosuccinimide (NCS), leading to the synthesis of $\beta$-chlorotetrahydrofurans [15]. Recently we have reported that visible-light-induced photoredox catalysis could serve as a more environmentalfriendly alternative reaction system to obtain $\mathrm{Br}_{2}$ in situ from $\mathrm{CBr}_{4}$, an oxidative quencher of photoredox catalyst [16-22]. Thus, as part of difunctionalization of alkenes, with our continuous investigations on the photoredox catalytic reactions [16,23-27], herein we report our preliminary studies on visiblelight-induced photoredox-catalyzed bromoetherification of alkenols using $\mathrm{CBr}_{4}$ as the bromine source.

\section{Results and Discussion}

Our initial studies were focused on the reaction of alkenol 1a as a model reaction for optimizing the reaction conditions. We were encouraged by the discovery that when $\mathbf{1 a}, \mathrm{CBr}_{4}$ and $\mathrm{Ru}$ (bpy) ${ }_{3} \mathrm{Cl}_{2}$ were irradiated by blue LEDs in $\mathrm{MeCN}$ for 
4 hours, trans- $\beta$-bromotetrahydrofuran 2a was obtained via 5 -endo bromoetherification reaction, although the yield was only $31 \%$ (Table 1 , entry 2 ). We have reported the bromoetherification of compound 1a as an example in our previous article [16]. However, considering the value of this strategy for the synthesis of $\beta$-bromotetrahydrofurans and -tetrahydropyrans, further research were carried out to optimize the reaction conditions. Moreover, the stereochemistry of the bromotetrahydrofurans compound 2a was misidentified before. Herein, the stereochemistry of the bromotetrahydrofurans compound 2a was determined by NOE spectra, for details see Supporting Information File 1. After a screening of selected solvents, we found solvents had a significant effect on the reaction effi- ciency (Table 1, entries 1-5). The reaction in DMSO led to the highest yield up to $94 \%$ (Table 1, entry 1). In addition, 2 equivalents of $\mathrm{CBr}_{4}$ were required for the efficient transformation (Table 1, entries 6 and 7). Furthermore, when the catalyst loading was reduced to even $1 \mathrm{~mol} \%$, the reaction also gave a comparable result (Table 1 , entry 8 ). It should be pointed out that no reaction was observed in the absence of light or photocatalyst.

With the optimized reaction conditions in hand, various substituted butenols were subsequently investigated for the scope of the reaction. As shown in Table 2, electronically distinct styrenes ranging from electron-rich to electron-deficient

Table 1: Survey on the photocatalytic bromoetherification of alkenols.<smiles>COc1ccc(/C=C/CCO)cc1</smiles>

$1 \mathrm{a}$<smiles>COc1ccc(C2OCCC2Br)cc1</smiles>

2a

\begin{tabular}{llll}
\hline Entry & Conditions & Time $(\mathrm{h})$ & ${\text { Yield }(\%)^{\mathrm{b}}}^{\mathrm{a}}$ \\
\hline 1 & Standard conditions & \\
2 & $\mathrm{CH}_{3} \mathrm{CN}$ as solvent & 4 & 94 \\
3 & $\mathrm{DCM}$ as solvent & 4 & 31 \\
4 & $\mathrm{THF}$ as solvent & 12 & 28 \\
5 & $\mathrm{DMF}$ as solvent & 24 & 71 \\
6 & Only 1 equiv $\mathrm{CBr}_{4}$ was used & 22 & 77 \\
7 & Only 1.5 equiv $\mathrm{CBr}_{4}$ was used & 6 & 86 \\
8 & Only 1 mol \% $\mathrm{Ru}_{\mathrm{bpy}} \mathrm{Cl}_{3}$ was used & 5 & 90 \\
\hline
\end{tabular}

aStandard conditions: alkenol 1a (0.2 mmol, 1 equiv), $\mathrm{CBr}_{4}\left(0.4 \mathrm{mmol}, 2\right.$ equiv), $\mathrm{Ru}(\mathrm{bpy})_{3} \mathrm{Cl}_{2}(0.006 \mathrm{mmol}, 3 \mathrm{~mol} \%)$ in dry DMSO $(0.1 \mathrm{M})$ irradiated by blue LEDs ( $1 \mathrm{~W})$; bisolated yield.

Table 2: Photocatalytic bromoetherification of butenols. ${ }^{a}$

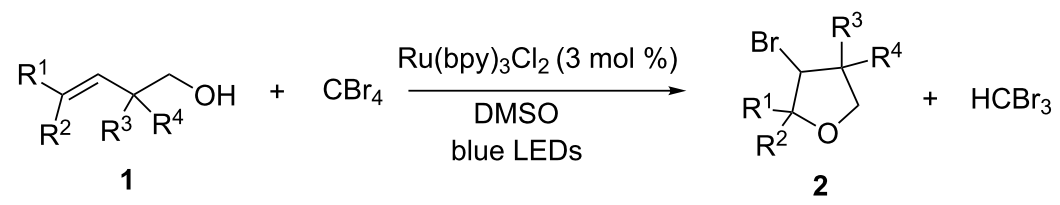

\begin{tabular}{|c|c|c|c|}
\hline Entry & Substrate & Product & Yield $(\%)^{\mathrm{b}}$ \\
\hline 1 & $\mathrm{R}=4-\mathrm{OMePh}$ & $2 a$ & 94 \\
\hline 2 & $\mathrm{R}=3-\mathrm{OMePh}$ & $2 b$ & 93 \\
\hline 3 & $\mathrm{R}=2-\mathrm{OMePh}$ & 2c & 89 \\
\hline 4 & $\mathrm{R}=\mathrm{Ph}$ & 2d & 88 \\
\hline
\end{tabular}


Table 2: Photocatalytic bromoetherification of butenols. ${ }^{a}$ (continued)

\begin{tabular}{|c|c|c|c|}
\hline 5 & $\mathrm{R}=4-\mathrm{MePh}$ & $2 e$ & 90 \\
\hline 6 & $\mathrm{R}=3-\mathrm{MePh}$ & $2 f$ & 85 \\
\hline 7 & $\mathrm{R}=2-\mathrm{MePh}$ & $2 g$ & 84 \\
\hline 8 & $\mathrm{R}=4-\mathrm{BrPh}$ & $2 \mathrm{~h}$ & 90 \\
\hline 9 & $\mathrm{R}=3-\mathrm{BrPh}$ & $2 \mathbf{i}$ & 87 \\
\hline 10 & $\mathrm{R}=2-\mathrm{BrPh}$ & $2 \mathbf{j}$ & 86 \\
\hline 11 & $\mathrm{R}=4-\mathrm{FPh}$ & $2 k$ & 89 \\
\hline 12 & $\mathrm{R}=4-\mathrm{NO}_{2} \mathrm{Ph}$ & 21 & 74 \\
\hline 13 & $\mathrm{R}=$ 2,4-diOMePh & $2 m$ & 93 \\
\hline 14 & $\mathrm{R}=$ 2,5-diOMePh & $2 n$ & 84 \\
\hline 15 & $\mathrm{R}=2-\mathrm{OMe}-5-\mathrm{CIPh}$ & 20 & 88 \\
\hline 16 & $\mathrm{R}=2-\mathrm{OMe}-\mathrm{naphthalen-1-yl}$ & $2 p$ & 86 \\
\hline 17 & $\mathrm{R}^{1}=4$-OTBDPSPh, $\mathrm{R}^{2}=\mathrm{Me}$ & $2 q$ & 87 \\
\hline 18 & $\mathrm{R}^{1}=\mathrm{R}^{2}=4-\mathrm{OMePh}$ & $2 r$ & 83 \\
\hline 19 & $\mathrm{MeO} \curvearrowright$ & & 90 \\
\hline
\end{tabular}

aStandard conditions: butenol 1 (0.2 mmol, 1 equiv), $\mathrm{CBr}_{4}\left(0.4 \mathrm{mmol}, 2\right.$ equiv), $\mathrm{Ru}(\mathrm{bpy})_{3} \mathrm{Cl}_{2}(0.006 \mathrm{mmol}, 3 \mathrm{~mol} \%)$ in dry $\mathrm{DMSO}(0.1 \mathrm{M})$ irradiated by blue LEDs (1W) for $4 \mathrm{~h}$; bisolated yield.

provided good yields of the desired 5-endo bromoetherification products (Table 2, entries 1-16). Additionally, trisubstituted alkenols were also examined and showed high reactivity (Table 2, entries 17 and 18). The alkenol with geminal dimethyl substituent produced the expected 5-endo bromoetherification product in $90 \%$ yield (Table 2 , entry 19 ).
To further demonstrate the general value of this strategy, a number of longer-chain pentenols were prepared and submitted to the optimized reaction conditions. As can be seen in Table 3, various styrenes were reacted efficiently to form the substituted tetrahydropyrans in high yield via 6-endo bromoetherification (Table 3, entries 1 and 2). Furthermore, not only primary alco-

Table 3: Photocatalytic bromoetherification of pentenols ${ }^{a}$.

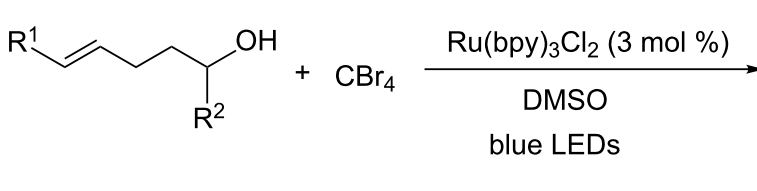

1

\begin{tabular}{|c|c|c|c|}
\hline Entry & Substrate & Product & Yield $(\%)^{\mathrm{b}}$ \\
\hline 1 & $\mathrm{R}=4-\mathrm{OMe}$ & $2 t$ & 91 \\
\hline 2 & $\mathrm{R}=4-\mathrm{Me}$ & $2 u$ & 87 \\
\hline
\end{tabular}


Table 3: Photocatalytic bromoetherification of pentenols ${ }^{a}$. (continued)

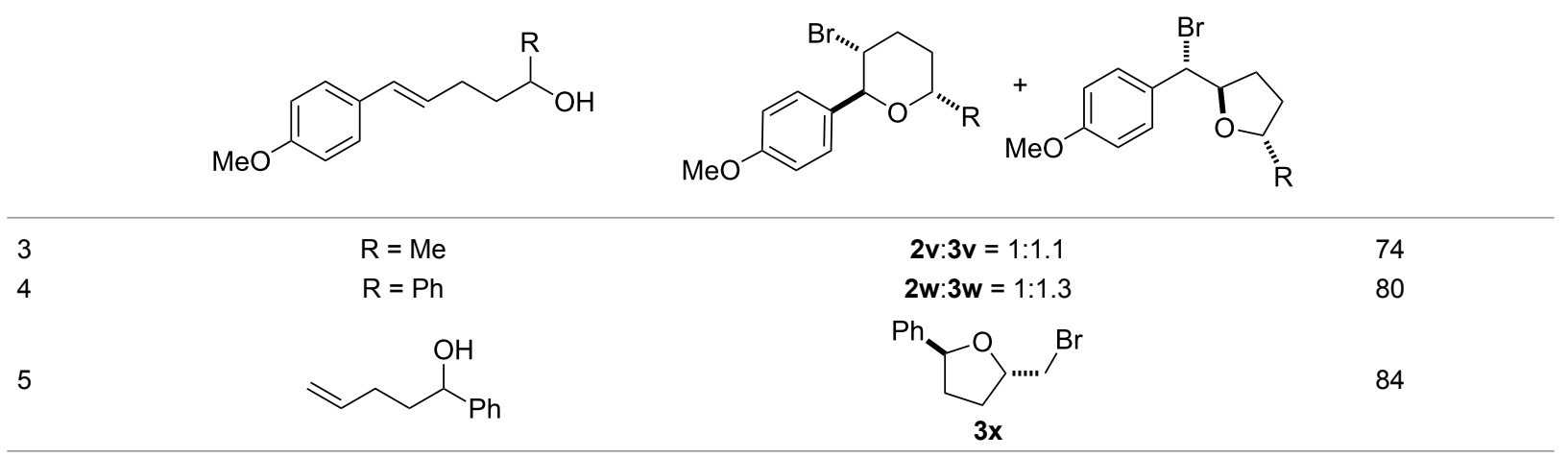

aStandard conditions: pentenol 1 (0.2 mmol, 1 equiv), $\mathrm{CBr}_{4}\left(0.4 \mathrm{mmol}, 2\right.$ equiv), $\mathrm{Ru}(\mathrm{bpy})_{3} \mathrm{Cl}_{2}(0.006 \mathrm{mmol}, 3 \mathrm{~mol} \%)$ in dry DMSO (0.1 M) irradiated by blue LEDs $(1 \mathrm{~W})$ for 4 hours; ${ }^{\text {isolated yield. }}$

hols but also secondary alcohols were tolerated using the reaction conditions albeit a mixture of 6-endo and 5-exo bromoetherification products obtained (Table 3, entries 3 and 4). Interestingly, for terminal alkene, the 5-exo bromoetherification product was achieved in $84 \%$ yield (Table 3 , entry 5 ).

To add more credence to the involvement of bromine in this protocol, a control experiment was conducted by reaction of alkenol 1a with liquid bromine in DMSO which led to trans- $\beta$ bromotetrahydrofuran $\mathbf{2 a}$ in $95 \%$ yield (Scheme 1). Such a result is in accordance with the case of $\mathbf{1 a}$ reacted under the standard reaction conditions of this protocol.

Based upon the above results, the mechanism is proposed as shown in Scheme 2. Firstly, oxidative quenching of the visiblelight-induced excited state $\mathrm{Ru}(\mathrm{bpy})_{3}{ }^{2+*}$ by $\mathrm{CBr}_{4}$, generates $\mathrm{Br}^{-}$ along with the $\mathrm{Ru}(\mathrm{bpy}) 3^{3+}$ complex. Then bromine was generated in situ through the oxidation of $\mathrm{Br}^{-}$by $\mathrm{Ru}(\mathrm{bpy}){ }_{3}{ }^{3+}[16]$, sequential reaction with alkene 1a forms the three-membered bromonium intermediate 4 [28]. Finally, intramolecular nucleo- philic cyclization furnishes the desired product $\beta$-bromotetrahydrofuran $\mathbf{2 a}$.

\section{Conclusion}

In summary, we have developed a mild and operationally simple method for the bromoetherification of alkenols with $\mathrm{CBr}_{4}$ as the bromine source, utilizing visible-light-induced phototedox catalysis. The reaction proceeds with high efficiency and regioselectivity for the synthesis of $\beta$-bromotetrahydrofurans and -tetrahydropyranes.

\section{Experimental}

\section{General procedure for the photocatalytic} bromoetherification of alkenols

To a $10 \mathrm{~mL}$ round bottom flask equipped with a magnetic stir bar were added alkenols 1 (0.2 mmol), $\mathrm{CBr}_{4}(132 \mathrm{mg}$, $0.4 \mathrm{mmol}), \mathrm{Ru}(\mathrm{bpy}){ }_{3} \mathrm{Cl}_{2}(4.6 \mathrm{mg}, 0.006 \mathrm{mmol})$ and dry DMSO $(2 \mathrm{~mL})$. The mixture was irradiated with blue LEDs $(1 \mathrm{~W})$ at room temperature without being degassed for 4 hours. Then water was added and the aqueous layer was extracted with ethyl

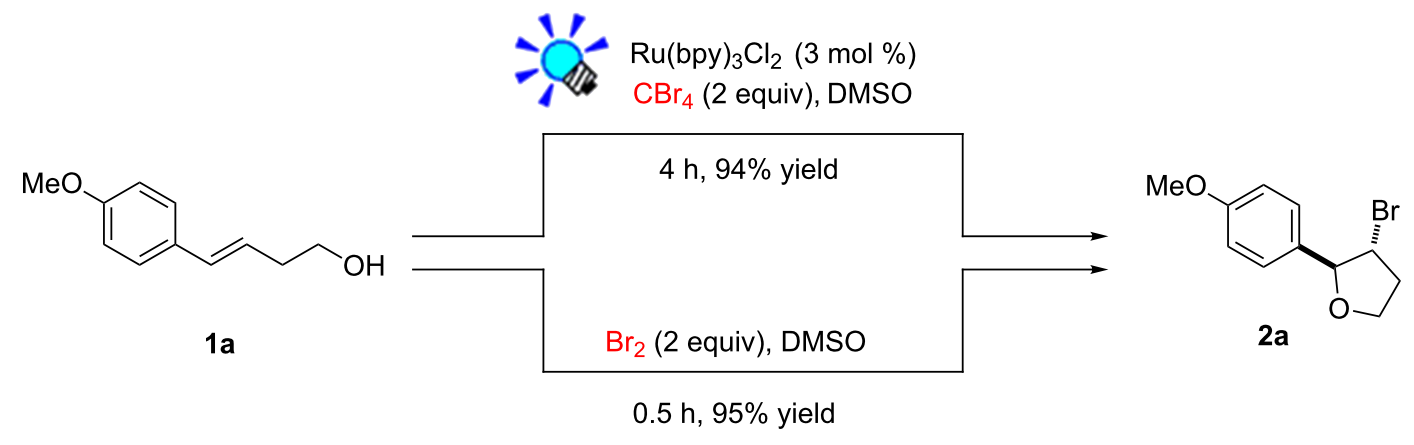

Scheme 1: Control experiment with liquid bromine for bromoethrification of alkenols. 


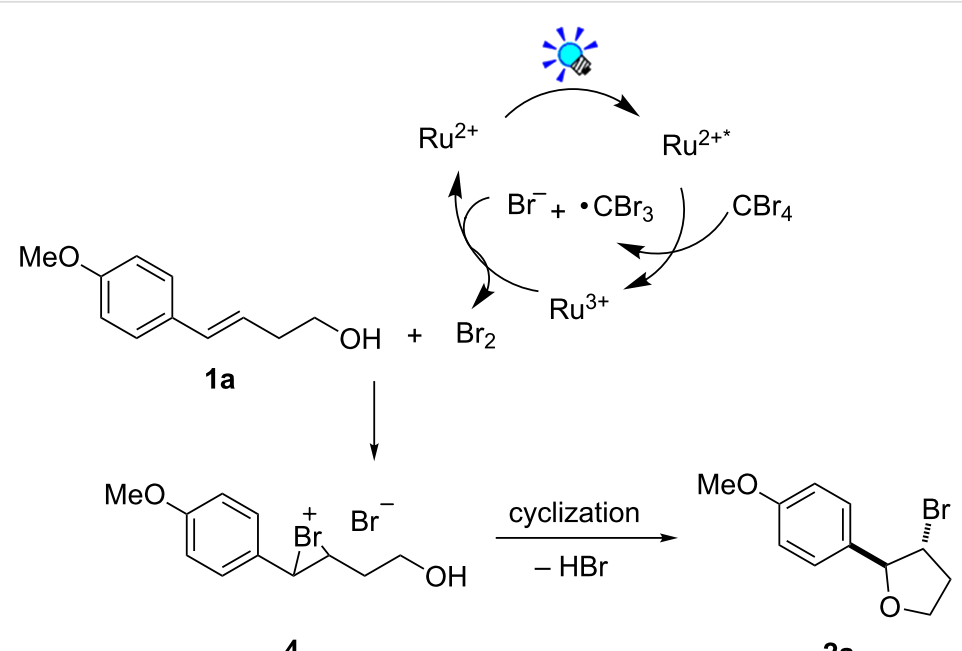

2a

Scheme 2: Proposed mechanism for the photocatalytic bromoetherification of alkenols.

acetate. The combined organic layers were washed with brine, dried over anhydrous $\mathrm{Na}_{2} \mathrm{SO}_{4}$ and concentrated. The residue was purified by flash column chromatography to give the final products 2 .

\section{Supporting Information}

\section{Supporting Information File 1}

${ }^{1} \mathrm{H}$ and ${ }^{13} \mathrm{C}$ NMR spectra for products.

[http://www.beilstein-journals.org/bjoc/content/ supplementary/1860-5397-11-5-S1.pdf]

\section{Acknowledgements}

We are grateful for the financial support from China NSFC (Nos. 21272047, 21372055 and 21472030), SKLUWRE (No. 2014DX01), the Fundamental Research Funds for the Central Universities (Grant No. HIT.BRETIV.201310) and HLJNSF (B201406).

\section{References}

1. French, A. N.; Bissmire, S.; Wirth, T. Chem. Soc. Rev. 2004, 33, 354-362. doi:10.1039/b310389g

2. Rodríguez, F.; Fañanás, F. J. In Handbook of Cyclization Reactions; Ma, S., Ed.; Wiley-VCH: New York, 2010; Vol. 4, pp 951-990.

3. Denmark, S. E.; Kuester, W. E.; Burk, M. T. Angew. Chem., Int. Ed. 2012, 51, 10938-10953. doi:10.1002/anie.201204347

4. Amjad, M.; Knight, D. W. Tetrahedron Lett. 2006, 47, 2825-2828. doi:10.1016/j.tetlet.2006.02.017

5. Cui, J.; Jia, Q.; Feng, R.-Z.; Liu, S.-S.; He, T.; Zhang, C. Org. Lett. 2014, 16, 1442-1445. doi:10.1021/ol500238k

6. Dowle, M. D.; Davies, D. I. Chem. Soc. Rev. 1979, 8, 171-197. doi:10.1039/cs9790800171

7. Ranganathan, S.; Muraleedharan, K. M.; Vaish, N. K.; Jayaraman, N. Tetrahedron 2004, 60, 5273-5308. doi:10.1016/j.tet.2004.04.014
8. Cardillo, G.; Orena, M. Tetrahedron 1990, 46, 3321-3408. doi:10.1016/S0040-4020(01)81510-6

9. Montaña, A. M.; Batalla, C.; Barcia, J. A. Curr. Org. Chem. 2009, 13, 919-938. doi:10.2174/138527209788452135

10. Staninets, V. I.; Shilov, E. A. Russ. Chem. Rev. 1971, 40, 272-283. doi:10.1070/RC1971v040n03ABEH001918

11. Cook, C.-h.; Cho, Y.-s.; Jew, S.-s.; Jung, Y.-H. Arch. Pharmacal Res. 1985, 8, 39-41. doi:10.1007/BF02897564

12. Feldman, K. S.; Crawford Mechem, C.; Nader, L. J. Am. Chem. Soc. 1982, 104, 4011-4012. doi:10.1021/ja00378a042

13. Crich, D.; Sartillo-Piscil, F.; Quintero-Cortes, L.; Wink, D. J. J. Org. Chem. 2001, 67, 3360-3364. doi:10.1021/jo016388d

14. Huang, D.; Wang, H.; Xue, F.; Guan, H.; Li, L.; Peng, X.; Shi, Y. Org. Lett. 2011, 13, 6350-6353. doi:10.1021/ol202527g

15. Zeng, X.; Miao, C.; Wang, S.; Xia, C.; Sun, W. Chem. Commun. 2013, 49, 2418-2420. doi:10.1039/c2cc38436a

16. Zhao, Y.; Li, Z.; Yang, C.; Lin, R.; Xia, W. Beilstein J. Org. Chem. 2014, 10, 622-627. doi:10.3762/bjoc.10.53

17. Zeitler, K. Angew. Chem., Int. Ed. 2009, 48, 9785-9789. doi:10.1002/anie.200904056

18. Yoon, T. P.; Ischay, M. A.; Du, J. Nat. Chem. 2010, 2, 527-532. doi:10.1038/nchem.687

19. Narayanam, J. M. R.; Stephenson, C. R. J. Chem. Soc. Rev. 2011, 40, 102-113. doi:10.1039/b913880n

20. Xuan, J.; Xiao, W.-J. Angew. Chem., Int. Ed. 2012, 51, 6828-6838. doi:10.1002/anie.201200223

21. Shi, L.; Xia, W. Chem. Soc. Rev. 2012, 41, 7687-7697. doi:10.1039/c2cs35203f

22. Prier, C. K.; Rankic, D. A.; MacMillan, D. W. C. Chem. Rev. 2013, 113, 5322-5363. doi:10.1021/cr300503r

23. Zhao, G.; Yang, C.; Guo, L.; Sun, H.; Chen, C.; Xia, W. Chem. Commun. 2012, 48, 2337-2339. doi:10.1039/c2cc17130a

24. Zhao, G.; Yang, C.; Guo, L.; Sun, H.; Lin, R.; Xia, W. J. Org. Chem. 2012, 77, 6302-6306. doi:10.1021/j0300796j

25. Sun, H.; Yang, C.; Gao, F.; Li, Z.; Xia, W. Org. Lett. 2013, 15, 624-627. doi:10.1021/ol303437m

26. Guo, L.; Yang, C.; Zheng, L.; Xia, W. Org. Biomol. Chem. 2013, 11, 5787-5792. doi:10.1039/c3ob41245h 
27. Sun, H.; Yang, C.; Lin, R.; Xia, W. Adv. Synth. Catal. 2014, 356, 2775-2780. doi:10.1002/adsc.201400476

28. Roberts, I.; Kimball, G. E. J. Am. Chem. Soc. 1937, 59, 947-948. doi:10.1021/ja01284a507

\section{License and Terms}

This is an Open Access article under the terms of the Creative Commons Attribution License

(http://creativecommons.org/licenses/by/2.0), which permits unrestricted use, distribution, and reproduction in any medium, provided the original work is properly cited.

The license is subject to the Beilstein Journal of Organic Chemistry terms and conditions:

(http://www.beilstein-journals.org/bjoc)

The definitive version of this article is the electronic one which can be found at: doi:10.3762/bjoc. 11.5 